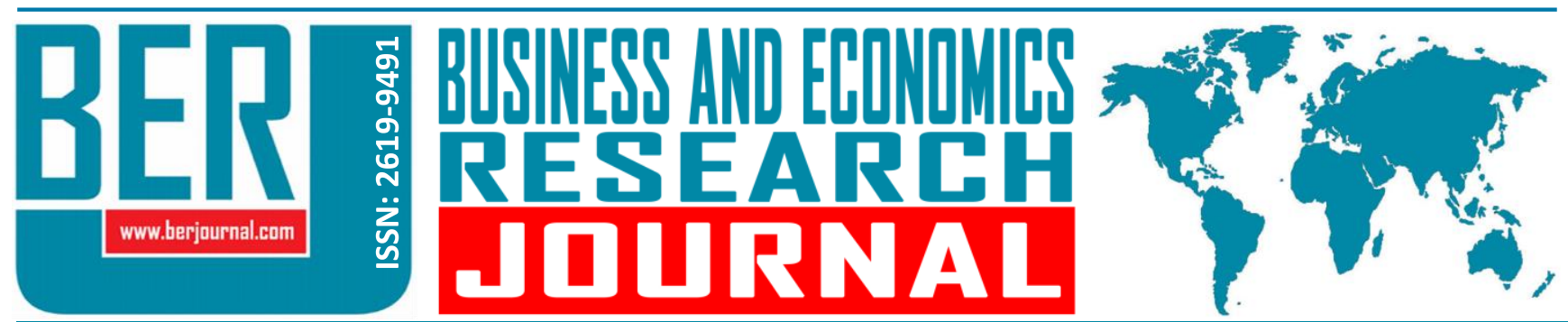

Business and Economics Research Journal Vol. 9, No. 3, 2018, pp. 449-462 doi: 10.20409/berj.2018.116

\title{
Market Structure of the Turkish Pharmaceutical Industry*
}

\author{
Egemen Ipek $^{\text {a }}$, Ozlem Ipek ${ }^{\mathrm{b}}$
}

Abstract: The market structure of the Pharmaceutical Industry, which has an extremely important both socially and economically position, is carefully monitored by regulatory authorities. The consantration of pharmaceutical companies tends to adversely affect consumer welfare as well as resource distribution in the economy. The competitive structure of the markets is determined by the concentration indices. For these reasons, in this study the market concentration ratios of the pharmaceutical sector in Turkey are calculated by using concentration measures such as Concentration Ratio; HerfindahlHirschman; Hall-Tideman; Rosenbluth; Comprehensive Industrial Concentration; Hannah-Kay; Hause and the Entropy measure with the annual sales revenue data of the companies in the sector for the 2009-2016 period.According to the results, pharmaceutical sector in Turkey has a low concentrated market structure. In addition, the Rosenbluth index presents the most consistent results for the Turkish pharmaceutical sector, which consists of hundreds of small companies having markets shares of $7 \%$ at the highest.

Keywords: Market Structure, Pharmaceutical Industry, Concentration Measures, Trend Analysis

JEL: D40, L10, L22 $\begin{array}{ll}\text { Received } & : 22 \text { February } 2018 \\ \text { Revised } & : 28 \text { March } 2018 \\ \text { Accepted } & : 18 \text { May } 2018\end{array}$

Type : Research

\section{Introduction}

The health problems and the diversity of diseases have been increasing as a result of changing the world's ecosystem affected by altering welfare level, demographics characteristics, living conditions of societies and increasing world population. In this context, the pharmaceutical sector plays a critical role on the global scale in terms of its potential effects on the extension of human life and increase of living standards (AIFD, 2012).

The pharmaceutical industry is generally defined as a sector which consists of companies specializing in research, development, production and distribution of drugs for medication. The pharmaceutical sector provides some important contributions such as discovery of new drugs, increase in the average life expectancy and quality of the healthcare sector as well as providing an important economic contribution by reducing the time spent in hospitals by reducing the need for medical examination and treatment. In addition to these important contributions, there is a fact that the discovery or development of new drugs depends on the existence of serious investments, qualified workforce and in-depth research. Therefore, the

a Asst. Prof., PhD., Gumushane University, Faculty of Economics and Administrative Sciences, Department of Economics, Gumushane,Turkiye eipek@gumushane.edu.tr (ORCID ID : 0000-0002-1365-0526)

b Lecturer, Gumushane University, Faculty of Economics and Administrative Sciences, Department of Economics, Gumushane,Turkiyr, osekmen@gumushane.edu.tr (ORCID ID : 0000-0002-3711-3258)

* Abstract version of this paper was presented at 8th Economics \& Finance Conference organized by IISES, which was held on May 29 - 31, 2017 at the University of London, United Kingdom.

Acknowledgement: We thank QuintilesIMS for providing “Turkey Pharmaceutical Index" used in this research. 
pharmaceutical industry is perceived as a 'value creating sector' and is regarded as a strategic sector by being considered as one of the priority investment areas in both developed- and emerging-countries.

In Turkey, considering the both large population and wide social security service of the country it can be said that the pharmaceutical sector is one of the top largest sectors with more than 30,000 employees. According to the US Department of Commerce 2016 Report, Turkey is the 29th largest pharmaceutical market in the world and the second largest market in Central / Eastern Europe. When the 2009-2016 Turkish pharmaceutical sector's annually box sales in terms of TL data ,which is provided by QuintilesIMS "Turkish Pharmaceutical Index", is examined it is observed that the sector have an increasing sales volume during the period. Figures 1a shows that box sales have increased from 14 billion boxes to 20 billion boxes between 2009 and 2016 with an average growth of around 4\%. Figures $1 \mathrm{~b}$ presents total sales revenue in TL have increased from 1.3 trillion TL to 2 trillion TL and the combined average annual (CAGR) has reached around $5 \%$ in the corresponding term.

On the other hand, when the total sales in terms of dollar in the same period are examined in the figure 1c, a downward trend is observed. The sales volume, which was $\$ 8.5$ billion in 2009, decreased to $\$$ 6.3 billion in 2016 and CAGR have declined by around 4\% in the corresponding period. However, this reduction is not caused by downsizing of the sector; but instead, it is the result of the TL depreciation by more than $9 \%$ compared to US Dollar in that period.

The pharmaceutical sector, which is one of the most essential (long-established) sectors of Turkey, has started to develop with the establishment of domestic and foreign pharmaceutical factories after 1952, and the entry of foreign capital into pharmaceutical market has contributed to the growth of the industry's production technology and infrastructure. Over the years, as a result of both R\&D in pharmaceutical sector has becoming very costly and company's product portfolio has been complementary, company mergers have been triggered. In addition, the global pharmaceutical sector players have bought local manufacturers of pharmaceutical companies in order to enter the emerging markets. These types of merger and acquisition agreements constitute about 50\% of the mergers occurred in the 2008 - 2010 period (AIFD, 2012). Considering the structure of the Turkish pharmaceutical industry, the question of how these mergers affect the structure of the industry and whether the government should allow or disallow these mergers can be answered by calculating the market concentration index.

Figures 1a,1b and 1c: Turkish Pharmaceutical Sector (2009-2016)

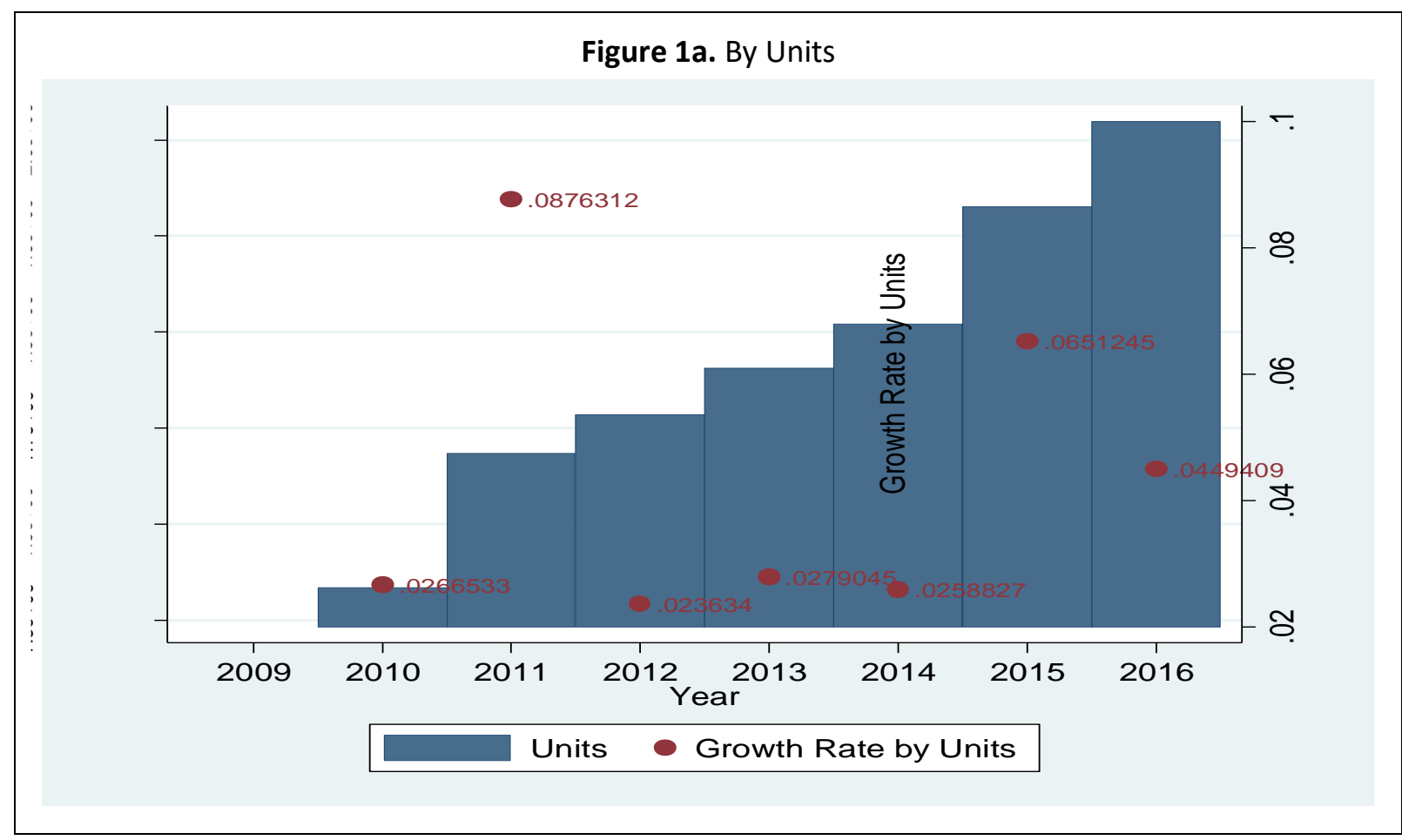




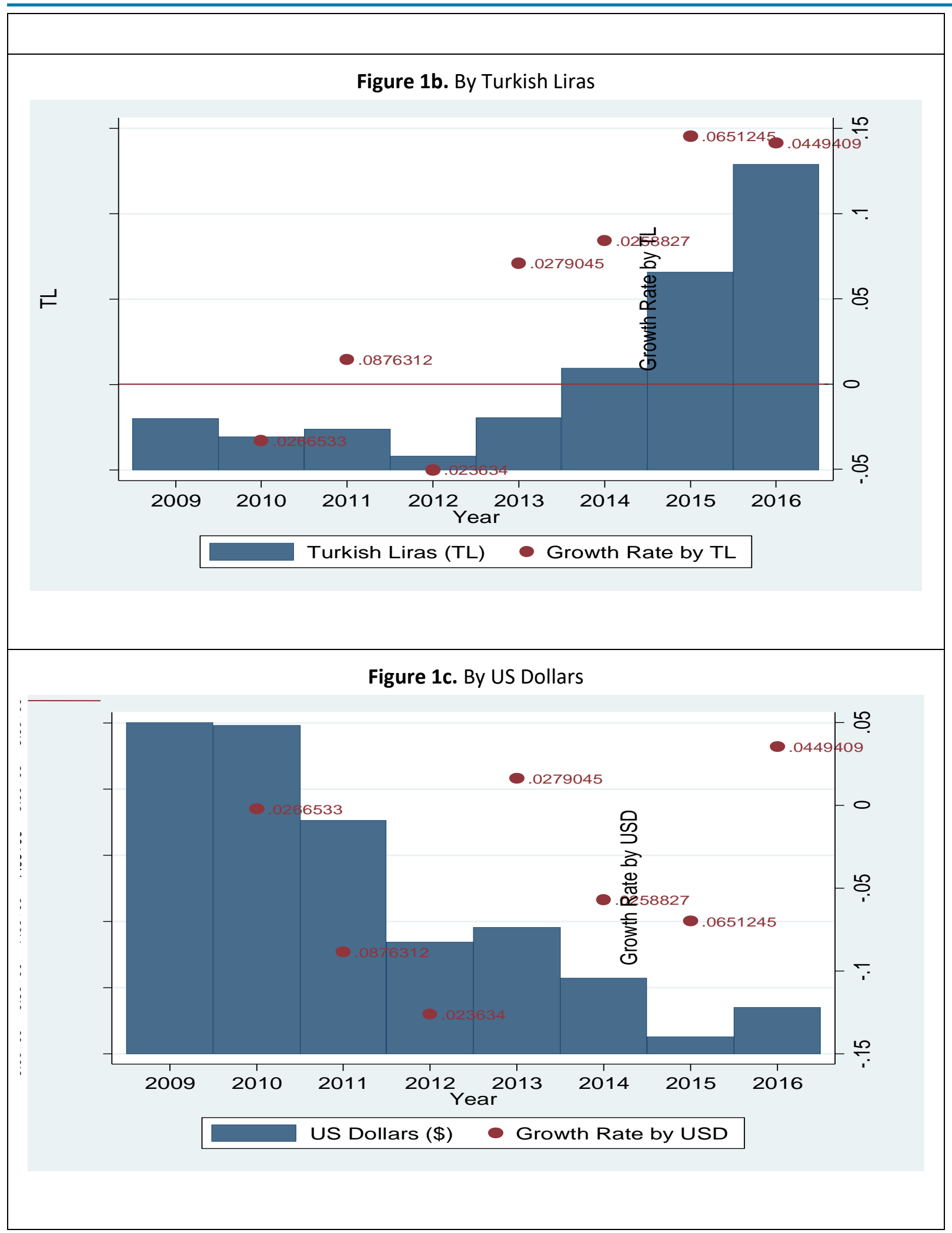

Source: Authors' adjustments based on QuintilesIMS “Turkish Pharmaceutical Index". 
Market concentration is a significant tool for measuring the competition among firms in an industry. Governments often use concentration measurements to decide whether merger should be allowed or not (Hennessy \& Lapan, 2007). One of the most used methods in calculating the market concentration index fourfirm concentration ratio $\left(C R_{4}\right)$ was first formally used in the 1968 Merger Guidelines. In 1982, the HerfindahlHirschman Index ( $\mathrm{HHI}$ ) replaced the $\mathrm{CR}_{4}$ index. The argument given for relying on the $\mathrm{HHI}$ rather than the $C R_{4}$ is the more comprehensive nature of the $\mathrm{HHI}$ (De Vany \& Kim, 2003: 5).

Industrial-organization economists agree that there is a close relationship between industry concentration and market performance (Bain, 1959; Koch, 1980; Tirole, 1988; Scherer, 1990; Jacquemin, 1987; Shy, 1995). Acording to Jacquemin \& Phlips (1976), more concentrated industries use their monopolistic power during upswings of the business cycle to increase selling prices more than would be justified by increase in demand and costs. For this reason, there are many concentration indices that can be calculated with the help of company market shares, which can be used in both econometric and anti-trust analyzes.

While many different indices and methods have been proposed for consistent calculation of the market concentration index that provides important information to decision makers, when the literature is examined, in fact, if their partial advantages left aside, there are basically eight firm concentration indexes. For this reason, in this study the market concentration ratios of the pharmaceutical sector in Turkey are calculated by using concentration measures such as the $\mathrm{k}$ firm Concentration Ratio $\left(C R_{k}\right)$; the HerfindahlHirschman Index ( $\mathrm{HHI})$; the Hall-Tideman Index (HTI); the Rosenbluth Index (RI); the Comprehensive Industrial Concentration Index (CCl); the Hannah and Kay Index (HKI); the Entropy measure (E); and the Hause Index (HI) with the annual sales revenue data of the companies in the sector for the 2009-2016 period. Using these indices the market concentration trend is estimated and the level of market concentration is forecasted for the next period.

The study consists of three parts. In the first part, pharmaceutical industry studies on concentration structure are mentioned. In the second part the concentration indices used in the study are explained and then the relevant concentration indices are calculated, and finally the trend of the concentration of the market is analyzed with OLS method. In the conclusion section, policy suggestions are offered by referring to the findings of the study.

\section{Literature Review}

The methods used in the calculation of the market concentration and the application of these methods on various industry branches are among most important issues in the field of industrial organization. The empirical application of market concentration indices focuses mainly on sectors such as automotive, banking, air transportation and manufacturing; while the number of studies conducted in the pharmaceutical sector has remained considerably limited.

Matraves (1999), calculates the $C R_{4}$ index for the Pharmaceutical Industry in Germany (1987-91), United Kingdom (1986-93), France (1985-92), Italy (1987-91), European Union (1987-93) and emphasizes that the market concentrations remained fairly stable in the periods for the all countries. According to the results, while the lowest $C R_{4}$ index is in France at 0.11 and the highest density is calculated in the UK at 0.35 .

In Sharp et al. (1996) study, the $C R_{1}, C R_{5}$ and $C R_{10}$ indices are calculated for Pharmaceutical Industry in Germany, France, the UK, Italy, Spain, Netherlands, Belgium, Greece, the USA and Japan for the 1988 and 1990 period. In the study, the lowest $C R_{5}$ index is calculated in Germany as 0.109 in 1988 and the highest $C R_{5}$, index is calculated in Greece as 0.283 followed by Netherlands with 0.267.

Chen \& Huaizhou (2001) calculate the concentration rates of the Chinese pharmaceutical industry using $\mathrm{HHI}$ and $C R_{k}$ indices for the 1990 and 1996 period. They conclude that the pharmaceutical industry has low concentration ratio for the corrseponding term the $C R_{4}$ index increases from 0.065 to 0.087 , the $C R_{8}$ index increases from 0.10 to $0.15, \mathrm{HHI}$ increases from 0.1884 to 0.2559 as well. 
Kontozamanis et al. (2003) emphasize that the Greek pharmaceutical market has a low concentration ratio for the year 2000 and conclude that $C R_{4}$ index is 0.256 for pharmaceutical companies, 0.216 for private wholesalers, and 0.203 for pharmacists' cooperatives. Competition is fierce in the area of therapeutic category. For example, the three leading companies in 2000 accounted for more than 0.30 of total sales in some categories.

Kassalis (2010) calculates $C R_{4}$ and $\mathrm{HHI}$ indices for the pharmaceutical industry in Latvia for the year of 2008. $C R_{4}$ is calculated as 0.95 and $\mathrm{HHI}$ as 0.484 for the pharmaceutical sector consisting of 22 firms. According the results, there is a high concentration for the pharmaceutical sector in Latvia due to the market barriers for new entrants.

Balili (2016) calculates $C R_{4}$ and $\mathrm{HHI}$ indices for the Albania pharmaceutical sector consisting of 100 firms for the period 2012-2014. During the corresponding period, while $C R_{4}$ increases from 0.215 to 0.248 $\mathrm{HHI}$ decreases from 0.239 to 0.228 . As a result of these analyzes, it is concluded that although the Albanian pharmaceutical sector has a low concentrations, the trend of the concentration increases in that period and the market is dominated by 22 large firms.

Tushar (2016) analyzes the relationship among the various market concentration indices of the Indian pharmaceutical industry and the relationship between these indices and innovation for the years 2004-2014. In the study, HHI, Gini, Entropy and Rosenbluth indices are preferred as the concentration index. According the empirical findings, $\mathrm{HHI}$ index increases in the next 3 years, and innovation increases as the market concentration ratio in the Indian pharmaceutical sector decreases.

On the other hand, there are also a few studies suggest that different results will be obtained if the concentration indices calculated for the overall pharmaceutical market are calculated in accordance with the therapeutic classification (Schwartzman, 1976; Slatter, 1977; Lall, 1979; Fiuza and Lisboa, 2003 ; Sweeny, 2007a, 2007b).

In the first study of therapeutic classification, Vernon (1971), 18 therapeutic products classes within the United States ethical pharmaceutical industry $C R_{4}$ and $\mathrm{HHI}$ indices are calculated for 1964 and 1968 . As a result, for the years 1964 and $1968, C R_{4}$ is 0.68 and $\mathrm{HHI}$ is 0.160 and 0.174 , respectively.

Grabowski \& Vernon (1976) calculate the $C R_{4}, C R_{8}$ and $C R_{20}$ and $\mathrm{HHI}$ indices both for the US for the period 1962-73 and UK ethical drug market for the period 1957-1973. According the eemprical results, the average $C R_{4}$ for the UK is 0.28 and the $C R_{6}$ is 0.45 , and the average $C R_{4}$ for the US is $0.26, C R_{8}$ is 0.43 for the corresponding period. They also conclude that the value of market concentration indices increases when therapeutic classification is applied.

Fiuza \& Lisboa (2003) analyze the effect of the degree of concentration on leaders' price, relative price of similar and generic drugs over the Brazilian pharmaceutical sector for the years between 1995 and 1999. They find that, the first 20 companies have 0.63 of the pharmaceutical industry for the year 1998 and the leader company has only the 0.065 of the market. The authors concluded that the Brazilian pharmaceutical sector has not had a very high concentration, but reaches a high concentration in the therapeutic class.

Sweeny (2007a) calculates $\mathrm{CR}_{4}, \mathrm{HHI}$ and Entropy indices for the Australian pharmaceutical market for the period 1991-2005. The lowest value of $C R_{4}$ index is calculated with 0.289 in 1999 while in 2003 it takes the highest value with 0.418 . HHI index takes the lowest value with 0.420 in 1994, it takes the highest value with 0.662 in 2003 . The author also emphasized that the explanatory power of the $C R_{4}$ index has decreased over the Entropy and $\mathrm{HHI}$ indices during the relevant period. In addition, it is argued that the market concentration has increased with the treatment market becoming more specific depending on therapeutic classification.

Mehta et al. (2016) divide the Indian pharmaceutical sector into five classes under the therapeutic classification. They calculate $\mathrm{HHI}$ indices for these subclasses instead of calculating the market concentration ratio for the Indian pharmaceutical sector by considering whole sector as a single market. They find that the 
overall market has a low concentration, with $0.226 \mathrm{HHI}$, but when it is divided into sub-markets according to drug formulation approximately 0.69 of the markets become moderate concentration.

Kaynak (2016) analyzes the concentration level of the Turkish pharmaceutical industry for the period 2005-2015 by distinguishing the between domestic and foreign companies. As a result of the study it is observed that the concentration rate of the Turkish pharmaceutical industry is low according to $C R_{4}$ and $C R_{8}$ indices, however the concentration is high and oligopolistic market structure is dominant according to $C R_{8}$ in the domestic companies in Turkish origin pharmaceutical sector and foreign companies in the foreignorigin pharmaceutical sector. On the other hand, it is observed that the concentration in both the domestic and imported pharmaceutical sector is not high when calculating by $\mathrm{HH}$ index. However; the studyof Kaynak is insufficient to represent the Turkish pharmaceutical industry since the study covers only 50 domestic and foreign companies which are the members of the Pharmaceutical Industry Employers Union. Therefore one of the most important contributions of current study is that it is extended to cover all firms in the Turkish pharmaceutical sector (approximately $450 \mathrm{firms}$ ) and the other one is the calculation of other concentration indices mostly used in the literature.

\section{Data, Methodology and Results}

In the study, the data provided by QuintilesIMS "Turkish Pharmaceutical Index" covers the warehouse sales of all companies operating in the Turkish pharmaceutical market for the 2009-2016 ${ }^{1}$ period. The IMS sales data audit, Turkish Pharmaceutical Index is the definitive measure of all medicinal product sales into retail pharmacies in Turkey. Although in 2009-2012 period there were a total of 435 companies 97 of them have remained out of the market during the period 2013-2016. However with the entrance of 121 new companies into the market the total numbers have increased to 459 at the end of the period.

The sales revenue of the companies in negative are updated to zero to avoid affecting the ranking of the company shares and included in the analysis with all companies with zero market shares. The market shares of the companies $\left(s_{i}\right)$ are calculated by dividing the total market sales revenue $\left(Q=\sum_{i=}^{n} q_{i}\right)$ in dollars by the company's sales revenue $\left(q_{i}\right)$.

$$
s_{i}=\frac{q_{i}}{Q}
$$

In the study eight concentration indeces are be used to calculate the market concentration of the pharmaceutical industry. These are the firm Concentration Ratio $\left(C R_{k}\right)$; The Herfindahl-Hirschman Index (HHI); The Hall-Tideman Index (HTI); The Rosenbluth Index (RI); The Comprehensive Industrial Concentration Index (CCl); The Hannah and Kay Index (HKI); The Entropy measure (E); and the Hause Index (HI). For a detailed study of these indices, see the study of Biker and Haaf (2002).

First, it will begin with an explanation of the $C R_{k}$ index, which were first accepted by the US government in 1968, and $\mathrm{HHI}$ indices which have been accepted by the US government as a measure of market concentration since 1982 because of its more comprehensive. These two indices have been widely used in empirical studies since they are officially accepted by the US government.

i. Concentration Ratio $\left(\boldsymbol{C} \boldsymbol{R}_{\boldsymbol{k}}\right)$ :This index, which is preferred thanks to its simplicity and less data requirement, is defined as the sum of the market shares of the first $k$ firms with the largest share in the market. Although the choice of the value of the $k$ parameter depends on the researchers, it is usually taken as $\mathrm{k}=4$, and $\mathrm{k}=8$ in empirical applications. The $C R_{k}$ index takes a value between 0 (= perfect competition) and 1 (= monopoly) and is mathematically expressed in Equation 2:

$$
C R_{k}=\sum_{i=1}^{k} s_{i}
$$

ii. Herfindahl Hirschman Index (HHI): One of the most popular concentration indices, $\mathrm{HHI}$ Index is calculated by summing the squares of the market shares of all firms in the market and it is formulated as in Equation 3: The $\mathrm{HHI}$ index takes a value between $1 / n$ and 1 and index reaches the unity in the case of 
monopoly. The market structure can be determined as low, moderate, high concentrated according to the value of $\mathrm{HHI}$ index. ${ }^{2}$ The $\mathrm{HHI}$ index is more consistent than the $\mathrm{CR}$ because it gives less weight to small firms while giving more weight to larger firms and covers all firms on the market. Davies (1979) analyzed the sensitivity of the $\mathrm{HHI}$ to its two parts, which are the number of firms in the market and the the inequality in market shares among the different firms. He found that the index becomes less sensitive to changes in the number of firms the larger the number of firms in the industry.

$$
H H I=\sum_{i=1}^{n} s_{i}^{2}
$$

iii. Hall-Tideman (1967) Index (HTI): This index was first used by Hall \& Tideman (1967) and the authors have argued that the number of firms should be taken into account when calculating the concentration index. They calculated the HTI index by ordering companies from large to small, and numbering each company ( $i=1$ for the largest firm) as expressed in Equation 4 . $\mathrm{HTI}$ takes a value between $1 / n$ and 1 and if there is an infinite number of companies in the same denominator it approaches to zero, whereas in monopoly it approaches to 1.

$$
H T I=\frac{1}{\left[\left(2 \sum_{i=1}^{n} i s_{i}\right)-1\right]}
$$

iv. Rosenbluth (1955) Index (RI): The author suggested that the ranking of company shares should be from small to large firm ( $i=1$ for the smallest firm), unlike the HTI index. Thus, giving more weight to the small firm density index is becoming more sensitive to the distribution of small firms. For this reason, Hause (1977) claims that Rosenbluth index is not appropraite for analyzing the market competition in highly concentrated industries.

Hart (1971) also proves that Rosenbluth index is a modified version of the Gini index. RI index takes a value between $1 / n$ and 1 , and approaches to 1 in the case of monopoly.

v. The Comprehensive Industrial Concentration Index (CCI): Hovarh (1970) emphasized that the problem of concentration and dispersion is important when determining the market structure. In the study, the author calculated $\mathrm{CCl}$ index for companies with different distributions through the following Equation 5 below. In the $\mathrm{CCl}$, which receives the theoretical form from $\mathrm{HHI}, \mathrm{s}_{1}$ refers the market share of the leading company, the rest of the equation represents the sum of squares of each company's share weighted by (1+(1$\left.s_{i}\right)$ ).

This last component decreases the effect of Herfindahl's geometric progression. Moreover, the purpose of this component to strengthen the capacity of $\mathrm{CCl}$ is not only to rank orders but also to mirror absolute features (Hovarth, 1970). While the CCI takes 1 in the monopoly case, it decreases to 0 in the perfect competition.

$$
C C I=s_{1}+\sum_{i=2}^{n} s_{i}^{2}\left(1+\left(1-s_{i}\right)\right)
$$

vi. The Hannah \& Kay (1977) Index (HKI), suggested that the concentration index of the market would be differrent depending on the distribution of small and large firms in the industry and they were calculated the index by using the formula shown by Equation 6 .

The value of $\alpha$ in the HKI index is the elasticity parameter. This value is equal to the number of firms when the limit goes to zero $\alpha \rightarrow 0$, while limit goes to infinity $\alpha \rightarrow \infty^{+}$the index is equal to the reciprocal of the largest firm. In addition, when $\alpha=2$, HKI is equal to the $\mathrm{HHI}$ index, and when $\alpha=1$, it is equal to Theil (1967) Entropy index. It implies that the value of the HKI index is closely related to the elasticity parameter $(\alpha)$. In general, while high $\alpha$ value focuses on the distribution of large firms, the low $\alpha$ value emphasizes the existence or absence of small firms. In the study of Hannah \& Kay (1977), the value of $\alpha$ is taken as $0,0.6,0.8,1.0,1.2,1.4,1.6,1.8,2.0,2.5$. However there is no criterion on the selection of the 
elasticity parameter, it is entirely under the initiative of the researcher. It is also said that as the HKI value decreases when the concentration of the market increases.

In generally speaking, when the HKI value decreases, the market concentration increases. This index is especially advantageous when comparing periods and showing the how market power of large firms are affected by entering or leaving the market of small companies.

$$
H K I=\left(\sum_{i=1}^{n} s_{i}^{\alpha}\right)^{1 /(1-\alpha)} \alpha>0 \text { and } \alpha \neq 1
$$

vii. The Hause (1977) Index (H): Hause (1977) proposed two new concentration indexes considering the collusion or agreement between the companies in the market at the Cournout Nash equilibrium. HHI provides a lower bound for theoretically reasonable measures of industry concentration due to the implicit agreement or coalition between the companies (explicit or tacit coopertaion).

The first one of these indices: The multiplicatively-modified Cournot is computed as in the following equation and it is sensitive to the parameter, which takes a value between zero and $2(1 / 3)^{1.5}$.

$$
H=\sum_{i=1}^{n} s_{i}^{2-\left[\left(H H I-s_{i}^{2}\right)\right]^{\alpha}} \alpha \geq 0.15
$$

The value of $\alpha$ should be equal or bigger than $0.15(\alpha \geq 0.15)$ based on the convexity assumption. In the study, $\alpha$ was taken as $0.15,0.25,0.5,1$ and 2 and it was seen that the tendency to increase competition due to the increase in the number of firms was slower at low $\alpha$ value.

The second index is the additively-adjusted Cournot measure and is sensitive to the $\beta^{3}$ parameter.

$$
H=\sum_{i=1}^{n} s_{i}^{2}+\left[s_{i}\left(H H I-s_{i}^{2}\right]^{\beta}, \beta>1\right.
$$

viii. Entropy (E): The use of this Entropy term, which is borrowed from the theory of physics and information, as a concentration index was first discussed by M.O. Finkelstein \& R.M. Friedberg (1967) and then was used in the study of Stigler (1964) and Marfels (1972) (Hause, 1977). The entropy index takes a value between 0 and $\log _{2} n$, and there is an inverse relationship between the index value and the degree of concentration.

The Entropy as a measure of concentration has been presented in this article on the basis of a logarithm with base 2, as proposed by White (1982) (Biker \& Haaf, 2002).

$$
E=-\sum_{i=1}^{n} s_{i} \log _{2} s_{i}
$$

The market displays a monopolistic character when index takes the value of 0 , whereas all the firms in the market have equal shares and the concentration is at the lowest level when the index has the highest value of $\log _{2} n$. It has mathematically superior properties than other indeces (Marfels,1972).

As Table 1 shows, although the indices used in the literature have some advantages over each other, it is difficult to say that there is an index that stands out theoretically. In addition, in the study the use of different indices to observe how the market structure of the Turkish pharmaceutical sector has changed in the period 2009-2016 is also important in order to be able to observe this tendency more consistently. 
Table 1. The Market Concentration Indices Under Microscope

\begin{tabular}{|c|c|c|c|c|}
\hline Index & Interval & Advantages & Disadvantages & Interpretation \\
\hline CR & {$[0,1]$} & Easy to calculate & $\begin{array}{l}\text { Very simple index and no rules to } \\
\text { determine for the number of firms, } \\
\text { not covers all the firms in the } \\
\text { industry }\end{array}$ & $\begin{array}{l}\text { Monopoly } \\
\text { as it approaches to } 1\end{array}$ \\
\hline $\mathrm{HHI}$ & {$[0,1]$} & $\begin{array}{l}\text { Covers all firms in the industry, } \\
\text { easy to calculate, commonly used } \\
\text { in the literature }\end{array}$ & $\begin{array}{l}\text { Less sensitive to changes in the } \\
\text { number of firms the larger the } \\
\text { number of firms in the industry }\end{array}$ & $\begin{array}{c}\text { Monopoly } \\
\text { as it approaches to } 1\end{array}$ \\
\hline $\mathrm{HTI}$ & {$[1 / n, 1]$} & $\begin{array}{l}\text { Considers the number of firms in } \\
\text { the market, focuses on large firms. }\end{array}$ & \multirow{2}{*}{$\begin{array}{l}\text { Its usefulness for analyzing } \\
\text { departures from competition in } \\
\text { highly concentrated industries } \\
\text { seems quite dubious' }\end{array}$} & \multirow{2}{*}{$\begin{array}{c}\text { Monopoly } \\
\text { as it approaches to } 1\end{array}$} \\
\hline RI & {$[1 / n, 1]$} & $\begin{array}{l}\text { Considers the number of firms in } \\
\text { the market, focuses on small firms. }\end{array}$ & & \\
\hline $\mathrm{CCl}$ & {$[0,1]$} & $\begin{array}{l}\text { Takes account both absolute } \\
\text { percentage and relative dispersion } \\
\text { measures }\end{array}$ & Suitable for cartel markets & $\begin{array}{l}\text { Monopoly when it } \\
\text { approaches to } 1\end{array}$ \\
\hline HKI & {$\left[1 / s_{1}, n\right]$} & $\begin{array}{l}\text { Distribution of firms in the industry } \\
\text { is important }\end{array}$ & $\begin{array}{l}\text { Sensitive to the alpha parameter in } \\
\text { the index, and there is no definite } \\
\text { rule for choosing this parameter. }\end{array}$ & $\begin{array}{l}\text { Competitive, as the } \\
\text { index value rises }\end{array}$ \\
\hline $\mathrm{H}$ & {$[0,1]$} & $\begin{array}{l}\text { Considers possible collusion or } \\
\text { agreement between companies in } \\
\text { the market. }\end{array}$ & $\begin{array}{l}\text { Sensitive to the alpha parameter, } \\
\text { and there is no definite rule for } \\
\text { choosing this parameter. }\end{array}$ & $\begin{array}{c}\text { Monopoly } \\
\text { as it approaches to } 1\end{array}$ \\
\hline$E$ & {$\left[0, \log _{2} n\right]$} & $\begin{array}{l}\text { A general index used in physics and } \\
\text { information theory. It has } \\
\text { mathematical superiority. }\end{array}$ & $\begin{array}{l}\text { Difficult to compare it with other } \\
\text { indexes because the index range is } \\
\text { not between zero and one. }\end{array}$ & $\begin{array}{l}\text { Monopoly } \\
\text { as it approaches to } 0\end{array}$ \\
\hline
\end{tabular}

Source: Authors' Adjustments

Table 2. Concentration of Turkish pharmaceutical industry (2009-2016)

\begin{tabular}{|c|c|c|c|c|c|c|c|c|c|}
\hline Index & Para. & 2009 & 2010 & 2011 & 2012 & 2013 & 2014 & 2015 & 2016 \\
\hline \multirow{2}{*}{$C R_{k}$} & $k=4$ & 0.238 & 0.235 & 0.228 & 0.221 & 0.194 & 0.195 & 0.199 & 0.200 \\
\hline & $k=8$ & 0.401 & 0.399 & 0.388 & 0.376 & 0.344 & 0.336 & 0.331 & 0.335 \\
\hline HHI & & 0.030 & 0.030 & 0.029 & 0.027 & 0.025 & 0.024 & 0.023 & 0.023 \\
\hline$H T I$ & & 0.026 & 0.025 & 0.024 & 0.023 & 0.023 & 0.022 & 0.021 & 0.020 \\
\hline$R \boldsymbol{I}$ & & 0.0012 & 0.0012 & 0.0012 & 0.0012 & 0.0011 & 0.0011 & 0.0011 & 0.0012 \\
\hline$E$ & & 1.703 & 1.720 & 1.740 & 1.759 & 1.775 & 1.791 & 1.808 & 1.819 \\
\hline $\mathrm{CCl}$ & & 0.112 & 0.116 & 0.117 & 0.113 & 0.101 & 0.100 & 0.100 & 0.101 \\
\hline \multirow{4}{*}{$H K I$} & $\alpha=.005$ & 313.79 & 320.10 & 334.54 & 340.60 & 326.09 & 320.21 & 332.02 & 363.35 \\
\hline & $\alpha=.025$ & 134.55 & 142.17 & 146.62 & 151.36 & 147.04 & 147.41 & 153.91 & 165.23 \\
\hline & $\alpha=5$ & 22.45 & 22.21 & 22.41 & 23.57 & 27.57 & 27.84 & 27.33 & 26.90 \\
\hline & $\alpha=10$ & 18.76 & 18.26 & 18.10 & 19.00 & 22.38 & 22.30 & 21.60 & 21.11 \\
\hline \multirow{3}{*}{$H$} & $\alpha=.25$ & 0.0542 & 0.0528 & 0.0507 & 0.0481 & 0.0428 & 0.0413 & 0.0403 & 0.0400 \\
\hline & $\alpha=1$ & 0.0304 & 0.0298 & 0.0287 & 0.0274 & 0.0245 & 0.0237 & 0.0233 & 0.0231 \\
\hline & $\alpha=2$ & 0.0303 & 0.0297 & 0.0286 & 0.0273 & 0.0245 & 0.0237 & 0.0232 & 0.0231 \\
\hline
\end{tabular}

Source: Authors' calculations.

Table 2 presents all the concentration index results for the Turkish pharmaceutical industry for 20092016 period. When looking at the CR and $\mathrm{HHI}$, which are frequently used in the literature in the market structure and accepted by the official institutions of the countries, it is seen that both indices have been decreasing during the period. When especially focusing on $C R_{4}$ and $C R_{8}$, which are frequently used in literature, it is seen that during the years $C R_{4}$ has decreased from 0.238 to 0.200 and $C R_{4}$ from 0.401 to 0.335 . The decline in these indexes gives us the knowledge that competition in the market is increasing. 
There are also several studies comparing the concentration ratios for the first four companies in Turkey's pharmaceutical sector with ratios in other countries. According to Sharp et al. (1996) study, Turkish pharmaceutical sector is high concentrated than Germany, France, UK, Italy, Spain, Netherland, Belgium, the USA and Japan pharmaceutical industry. On the other hand, it is low concentrated than Greece according to Kontozamanis et al. (2003), Latvia according to Kassalis (2010) and Albania according to Balili (2016).

Looking at the $\mathrm{HHI}$ results, which is another frequently used index in the literature presented in Table 2 , it is seen that the index value declined from 0.030 to 0.023 over the years. It means that the concentration of market structure is gradually declining. However, when Turkish pharmaceutical industry $\mathrm{HHI}$ ratio compared with other countries, Turkish pharmaceutical industry is seen as having a more concentrated market structure.

When looking at HTI index, which focuses on the number of firms in the pharmaceutical industry and the largest firm in the market, it can be said that the index value has decreased from 0.026 to 0.020 and the competitive structure has increased. However, considering the structure of the Turkish pharmaceutical sector (consisting of many small firms with a maximum of $7 \%$ market share) it is expected that the Rosenbluth index, which focuses on small firms, will provide more consistent information about the direction of the competitive structure of the market. Indeed, during the 2009-2016 period, the RI index is approximately 0.0012 . From this perspective, it can be said that there is no change in the competitive structure of the Turkish pharmaceutical sector in the corresponding period.

When $\mathrm{CCl}$ and Entropy indices are examined, it can be said that the pharmaceutical sector structure of Turkey has a more competitive structure in 2009-2016 period, consistent with other indices. However, unlike the $C R_{k}, \mathrm{HHI}$ and $\mathrm{HTI}$ indices, the competitive structure of the market has changed less. This change is $9 \%$ according to $\mathrm{CCl}$ and $6 \%$ for Entropy index. While both indices show that there is no significant change in the market structure, considering that $\mathrm{CCl}$ is a more effective measure in the market for cartel features, it can be said that the $\mathrm{CCl}$ is not sufficient to determine the changes in Turkish pharmaceutical market structure.

Finally when the $\mathrm{HKI}$ and Hause indices, which are closely related to the obtained index values with $\alpha$ parameter used in the model, are examined it is assumed that when the $\alpha$ parameter is small the smallest change in the share of big firms will affect the structure of market competition considerably because of small firms entering or leaving the market. In this respect, HKI index value is 313.79 when $\alpha=0.005$, while when $\alpha$ $=10$, the index value is 18.76 . In other words, it can be said that the market has a more competitive character due to the existence of small firms. It can be argued that the market structure of the Turkish pharmaceutical sector has gained a more competitive character during the period of 2009-2016 by looking at the results of both indices. However, due to the fact that there are no leading companies with high shares in the Turkish pharmaceutical sector market, a large selection of the $\alpha$ parameter is recommended and in this case it is seen that the index values have less changed in the corresponding period.

Figure 2. Actual and Estimated Values of Selected Indices

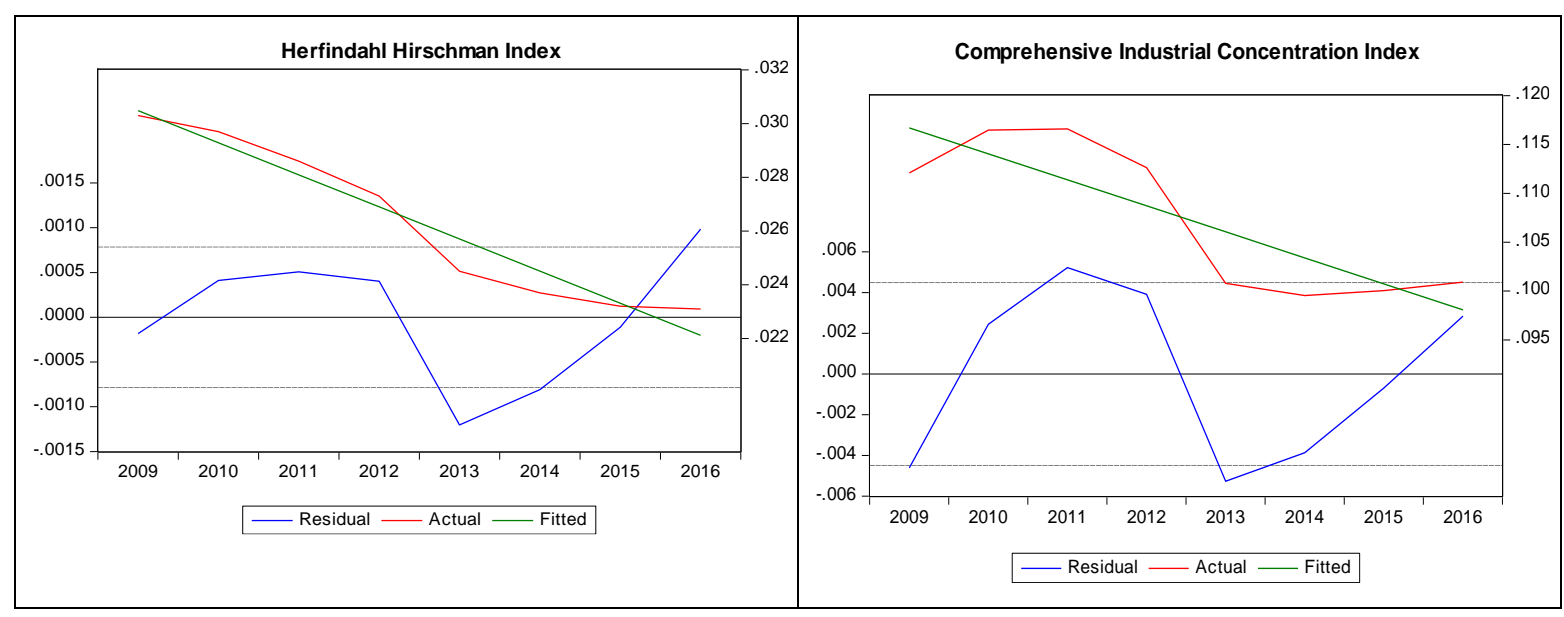




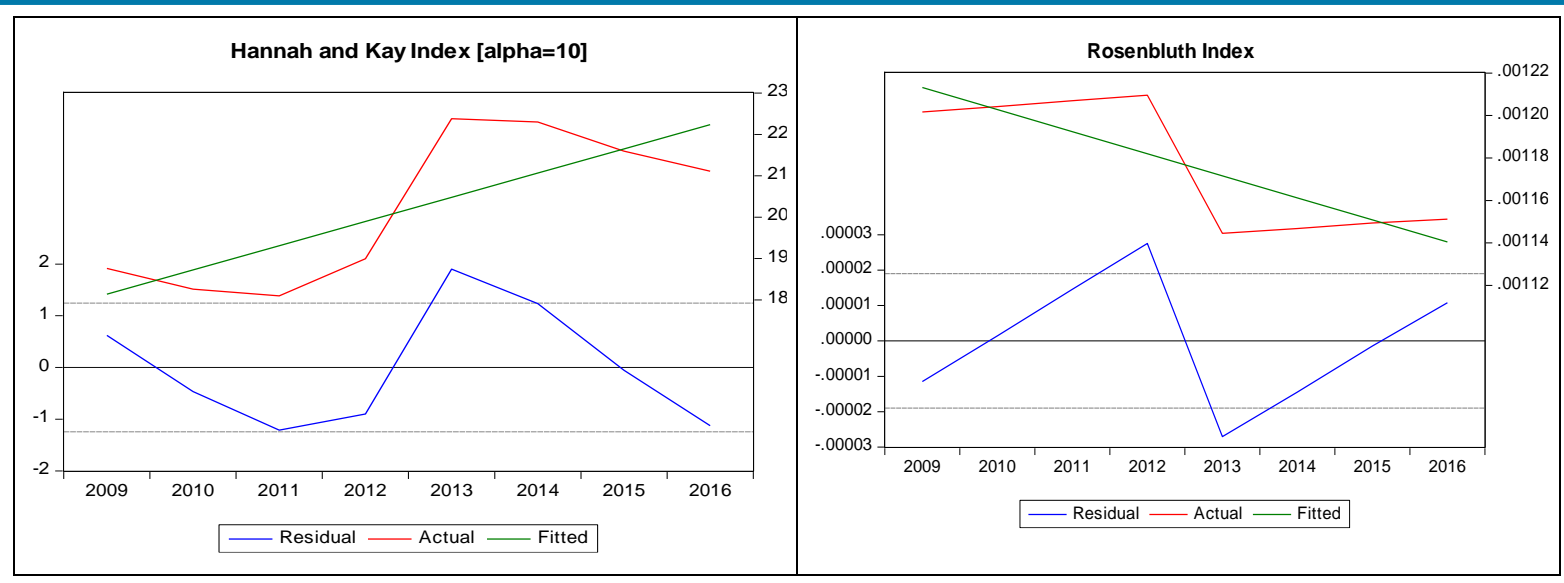

Source: Authors' calculations.

Finally, the trend analysis of the change in the market structure of the Turkish pharmaceutical sector was estimated by using the OLS method through selected market intensity indices. ${ }^{4}$ The HerfindahlHirschman and Comprehensive Industrial Concentration indices are chosen because they are frequently used indices in the literature, Rosenbluth and Hannah \& $\operatorname{Kay}(\alpha=10)$ indexes are chosen as well with the assumption that they represent the Turkish pharmaceutical sector structure better. It is estimated that the market structure of the Turkish pharmaceutical sector will be even less concentrated in the coming years as an estimate of the trend models in which each of these indices is independent variable.

In the $\mathrm{HHI}$ and $\mathrm{CCl}$ models, when the trend coefficients of the market intensity are examined, it is seen that the coefficients are statistically significant and take the value of $-0.0012,-0.00266$ respectively. In the RI model, the trend coefficient is statistically significant and is -0.00001 . Comparing these three models, it can be said that the competitiveness of the market will increase according to all models, but the change in competitive structure according to the Rosenbluth index will be very low during the period. On the other hand, unlike other indices, the highest $\mathrm{HHI}$ index represents a highly competitive market structure. There is a statistically significant correlation between the competitive structure and the higher value of HKI in the period.

In conclusion, the competitive structure of the Turkish pharmaceutical sector has an increasing trend, but this trend is likely to be slower in the RI and HKI models.

\section{Conclusion}

One of the important results obtained from the study, which examines the market structure of the Turkish pharmaceutical sector between 2009 and 2016 using the market concentration indices such as the $\mathrm{k}$ firm Concentration Ratio $\left(C R_{k}\right)$; the Herfindahl-Hirschman Index $(\mathrm{HHI})$; the Hall-Tideman Index $(\mathrm{HTI})$; the Rosenbluth Index (RI); the Comprehensive Industrial Concentration Index (CCI); the Hannah and Kay Index (HKI); the Entropy measure (E); and the Hause Index ( $\mathrm{HI})$, is that the market has a low concentration during the corresponding period.

In the study, when the $C R_{4}, C R_{8}$ and $\mathrm{HHI}$ concentration ratios, which are frequently used in the literature, for Turkey's pharmaceutical sector is compared with ratios in other countries it is seen that Turkey has a more concentrated market structure. In this perspective, it is seen that although Turkish pharmaceutical sector is considered as low concentrated market structure, it has a more iconcentrated market structure compared to most developed and developing countries. Especially among the first eight pharmaceutical sector companies with the highest market share in Turkey there are only two domestic pharmaceutical companies which are Abdi İbrahim and Bilim. In this regard, policies targeting to increase the share of companies with domestic capital by reducing the concentration of the Turkish pharmaceutical industry to the level of developed countries may be applied by policy makers. 
Considering the advantages and disadvantages of the market concentration indices, it can be said that the Rosenbluth index gives the most consistent result in Turkish pharmaceutical sector consisting of hundreds of small firms with low shares where the highest market share is around $7 \%$. It is also thought that the Hannah and Kay index, which allows more emphasis on small firms with the help of $\alpha$ elasticity parameter, provides more flexible and consistent results for Turkish pharmaceutical industry than the $C R_{k}$ and $\mathrm{HHI}$ indices frequently used in the literature. Finally, in the study, it should not be forgotten that the consideration of the Turkish pharmaceutical industry as a collective market brings a limited approach to revealing the intensity structure of the market. As in the study of Mehta, Farooqui \& Sevaraj (2016), analyzing the pharmaceutical industry by separating it into sub-markets rather than as a single market will allow for more detailed results for the Turkish pharmaceutical sector. For this reason, it is suggested that further studies should examine the pharmaceutical market by dividing in to several sub-markets under the therapeutic classification.

\section{End Notes}

1. Companies which are used in the provision of data by IMS Health Database entered Turkey's market in 2009. So the data set can be provided by this date. The most update data that can be accessed from 2016.

2. For European Commission is Low(<0.1); Moderate(0.1-0.2); High (>0.2), for US Department of Justice and US Federal Trade Commission are Low(<0.15); Moderate(0.15-0.25); High (>0.25).

3. $\beta=1$, the index reaches to $2 / n$, instead of $1 / n$ and reaches to $1 / n^{\beta}$ when $\beta<1$.

4. See Appendix 1.

\section{References}

Araştırmacı Illaç Firmaları Derneği (AIFD) (2012). Türkiye ilaç sektörü vizyon 2023 raporu.

Bain, J. S. (1959). Industrial organization. New York: John Wiley \& Sons Press.

Balili, L. (2016). Analyzing competition in pharmaceutical sector-with a case study of Albania. European Scientific Journal, 12(15),132-142.

Bikker, J. A., \& Haaf, K. (2002). Measures of competition and concentration in the banking industry: A review of the literature. Economic \& Financial Modelling, 9(2): 53-98.

Chen, L., \& Huaizhou, T. (2001). The study of market concentration of pharmaceutical industry in China. China Pharmacy, 1, 001-012.

Davies, S. (1979). Choosing between Concentration Indices: The iso-concentration curve. Economica, 46(181),67-75. Doi:10.2307/2553097

De Vany, A,. \& Kim, C. L. H. (2003). Stochastic market structure: Concentration measures and motion picture antitrust. No. 30701. University of Manchester, Institute for Development Policy and Management (IDPM).

Finkelstein, M. O., \& Friedberg, R. M. (1967). The application of an entropy theory of concentration to the Clayton Act. The Yale Law Journal, 76(4), 677-717.

Fiuza, E. PS, \& Lisboa, M.de B. (2003). Credence goods and market power: An econometric study on the Brazilian pharmaceutical industry. Estudos Econômicos, 33(4), 601-638.

Grabowski, H. G., \& Vernon, J. M. (1976). Structural effects of regulation on innovation in the ethical drug industry. Essays on industrial organization, in honor of Joe S. Bain.

Hall, M., \& Tideman, N. (1967). Measures of concentration. Journal of the American Statistical Association, 62(317), 162168.

Hannah, L., \& Kay, J. A. (1977). Concentration in modern industry: Theory, measurement and the UK experience. Springer. Hart, P.E. (1971). Entropy and other measures of concentration, Journal of the Royal Statistical Society, 134, 73-85.

Hause, J. C. (1977). The measurement of concentrated industrial structure and the size distribution of firms. Annals of Economic and Social Measurement, 6(1), 73-107. 
Hennessy, D. A., \& Lapan, H. (2007). When different market concentration indices agree. Economics Letters, 95(2), 234240.

Horvath, J. (1970). Suggestion for a comprehensive measure of concentration. Southern Economic Journal, 36(4), 446452.

Jacquemin, A. (1987). The new industrial organization. Cambridge, Mass.: MIT Press.

Jacquemin, A. P., \& Phlips, L. (1976). Concentration, size and performance of European firms. In Markets, corporate behaviour and the state, 55-77. Boston, MA: Springer

Kassalis, I. (2010). Cluster-Based Approach: A tool to enter into the market In Business and Management 2010, conference selected papers. Vilnius, 635-642.

Kaynak, S. (2016). Türk ilaç sektörünün rekabet yapısı ve yoğunlaşma analizi. Çankırı Karatekin Üniversitesi iiBF Dergisi, 6(2), 49-66.

Koch, James V. (1980). Industrial Organization and Prices. Englewood Cliffs, NJ: Prentice-Hall.

Kontozamanis, V., Mantzouneas, E., \& Stoforos, C. (2003), An overview of the Greek pharmaceutical market. Eur. J. Health Econ., (4), 327-333

Lall, S. (1979). Multinational Companies and Concentration: The Case of the Pharmaceutical Industry. Social Scientist, 7(8/9), 3-29. Doi:10.2307/3516706

Marfels, C. (1971). Absolute and relative measures of concentration reconsidered. Kyklos 24, 753-766.

Marfels, C. (1972). The consistency of concentration measures: A mathematical evaluation. Journal of Institutional and Theoretical Economics, 196-215.

Matraves, C. (1999). Market structure, R\&D and advertising in the pharmaceutical industry. The Journal of Industrial Economics, 47(2), 169-194.

Mehta, A., Farooqui, H. H., \& Selvaraj S. (2016). A critical analysis of concentration and competition in the Indian pharmaceutical market. PloS one, 11(2), e0148951.

QuintilesIMS, Turkish Pharmaceutical Index 2009-2016

Rosenbluth, G. (1955). Measures of concentration. Business concentration and price policy. Princeton University Press, 57-99.

Scherer, F.M. (1990). Industrial market structure and economic performance. Boston.

Schwartzman, D. (1976). Innovation in the pharmaceutical industry, Johns Hopkins University Press.

Sharp, M., Patel, P., \& Pavitt, K. (1996). Europe's pharmaceutical industry: an innovation profile. European Commission. Shy, O. (1995). Industrial organization: theory and applications. MIT press.

Slatter, S. St. P. (1977). Competition and marketing strategies in the pharmaceutical industry. London, Croom Helm.

Stigler, G.J. (1964). A theory of oligopoly. Journal of Political Economy, 72, 44-61.

Sweeny, K. (2007a). The pharmaceutical industry in Australia. Working Paper No. 34, Centre for Strategic Economic Studies, Victoria University of Technology, Melbourne.

Sweeny, K. (2007b). Trends and outcomes in the Australian pharmaceutical benefits scheme. Pharmaceutical Industry Project Working Paper No. 36, December, Centre for Strategic Economic Studies, Victoria University, Melbourne

Theil, H. (1967). Economics and information theory, Studies in Mathematical and Managerial Economics. Noord- Holland Publishing Company.

Tirole, J. (1988). The theory of industrial organization. Cambridge, Mass.

Tushar, M. (2016). Determinants of market concentration and market power in Indian Pharmaceutical Industry. DOI: 10.13140/RG.2.1.4799.4086

U.S. Department of Commerce (2016). ITA pharmaceuticals top markets reports country case study: Turkey, May 2016.

U.S. Department of Justice, Merger Guidelines (1968).

U.S. Department of Justice, Merger Guidelines (1982).

Vernon, J. (1971). Concentration, promotion, and market share stability in the pharmaceutical industry. The Journal of Industrial Economics, 19(3), 246-266. Doi:10.2307/2097429

White, A.P. (1982). A note on market structure measures and the characteristics of the markets that they 'measure'. Southern Economic Journal, 49 (02), 542-549. Doi10.2307/1058503 


\section{Appendix}

Appendix 1. OLS Estimation Results

\begin{tabular}{|lrrrr|}
\hline Variables & HHI & CCI & \multicolumn{1}{c|}{ RI } & \multicolumn{1}{c|}{ HKI10 } \\
\hline Cons & $0.03048^{*}$ & $0.11669^{*}$ & $0.00121^{*}$ & $18.13992^{*}$ \\
& $(0.00051)$ & $(0.00290)$ & $(0.00001)$ & $(0.80290)$ \\
Trend & $-0.0012^{*}$ & $-0.00266^{*}$ & $-0.00001^{*}$ & $0.58502^{* *}$ \\
& $(0.00012)$ & $(0.00069)$ & $(0.00000)$ & $(0.19193)$ \\
Model Results & & & & \\
\hline R $^{\wedge}$ & 0.94193 & 0.71030 & 0.67700 & 0.60761 \\
Adjusted R^2 & 0.93225 & 0.66202 & 0.62317 & 0.54221 \\
S.E. of regres. & 0.00079 & 0.00449 & 0.00002 & 1.24385 \\
Sum squared res & 0.00000 & 0.00012 & 0.00000 & 9.28300 \\
Log likelihood & 46.9960 & 33.0447 & 76.7730 & -11.9465 \\
F-statistic & 97.3239 & 14.7110 & 12.5760 & 9.2909 \\
Prob(F-statistic) & 0.00006 & 0.00860 & 0.01213 & 0.02257 \\
Mean depen. var & 0.02630 & 0.10739 & 0.00118 & 20.1875 \\
S.D. depen. var. & 0.00302 & 0.00773 & 0.00003 & 1.83839 \\
Akaike info & -11.2490 & -7.7612 & -18.6933 & 3.4866 \\
Schwarz & -11.2291 & -7.7413 & -18.6734 & 3.5065 \\
Hannan-Quinn & -11.3830 & -7.8951 & -18.8272 & 3.3527 \\
Durbin-Watson & 1.2946 & 1.3878 & 1.8332 & 1.3918 \\
\hline
\end{tabular}

Notes: The standard errors are in parentheses. ${ }^{*}$ and $* *$ indicate statistical significance at the $1 \%$ and $5 \%$ 